\title{
LA IDEOLOGÍA Y LA CAMISETA: LOS EXILIADOS ARGENTINOS ANTE EL MUNDIAL 78
}

\author{
Antonio Gómer. \\ Tulane University \\ agomez@tulane.edu
}

Resumen: Las comunidades de exiliados argentinos en los setenta fueron muy activas en su denuncia del programa dictatorial, especialmente respecto de los abusos de derechos humanos, pero su activismo fue menos prominente durante la celebración de la copa mundial de fútbol en Argentina en 1978. El boicot del evento propuesto desde Francia tuvo muy poca repercusión entre los exiliados, contradicción que explicaron disociando la lógica política de la deportiva, o prefirieron dejar sin explicación. De hecho, en el corpus de textos del exilio, el Mundial tiene una presencia casi nula. Por su parte, Osvaldo Soriano opta por una representación alegórica del evento en su novela Cuarteles de invierno.

Palabras clave: Fútbol, Mundial 78, Argentina, Soriano, Alegoría.

\begin{abstract}
The Argentine exile communities in the 1970 s were very active denouncing the dictatorial programme, especially with regard to human rights abuses. However, their activism was less prominent during the 1978 World Cup held in Argentina. The boycott of the event proposed from France had very little repercussion among the exiles: a contradiction that they explained by dissociating political logic from sporting logic, or preferred to leave it unexplained. In fact, in the exile texts' corpus, the World Cup has almost no presence. Though, Osvaldo Soriano chooses an allegorical representation of the event in his novel Cuarteles de invierno.
\end{abstract}

Keywords: Soccer, 1978 World Cup, Argentina, Soriano, Allegory. 
Así recordaba Nicolás Casullo, veinte años después, cómo había vivido en su exilio mexicano la copa mundial 1978, celebrada en la Argentina de la dictadura:

Les anuncié a muchos que me compraría un televisor a colores, y así fue. Nos concentramos unos treinta en casa, siempre una hora antes de cada partido para discutir imaginariamente con el Flaco cada puesto y posicionamiento táctico. Festejamos cada gol como en lo más alto de la popular. Competíamos con otra gran concentración en la librería Gandhi para ver quién llevaba más público. En la final nos colgamos de las arañas y los balcones, y unos trescientos organizamos una extensa manifestación por cuadras y cuadras hasta coronar en el viejo Zócalo de México, donde paganamente danzamos dando gracias al viejo Alumni que había creado los cielos y la tierra y separado las aguas. (1998, p. 236).

La historia nos dice que la escena se repitió en cada lugar que albergara a un grupo significativo de exiliados argentinos: Caracas, Estocolmo, Madrid, Barcelona, París. Sin embargo, no es frecuente en las representaciones literarias o cinematográficas de esas comunidades de exiliados. No aparece, ni siquiera metaforizada, en la película de Fernando Solanas Tangos. Ni en El exilio de Gardel (1985), ni en la de Hugo Santiago Les trottoirs de Saturne (1985), ni en los textos de Osvaldo Soriano, Julio Cortázar o Antonio di Benedetto. La explicación de esta ausencia se encuentra en la forma esquizofrénica en que el exilio se enfrentó con el mundial. Por un lado, la conciencia sobre la maquinaria propagandística echada a rodar por la dictadura; por otro, el orgullo patriotero de que la Argentina fuera el epicentro del mundo del fútbol durante un mes. El sentido del deber con que se rechazaba toda operación del régimen, contra la pasión 
debida al deporte nacional. La oposición a la Junta, contra la lealtad hacia la selección; la vergüenza y el dolor por el exilio y el autoritarismo, contra la euforia por el triunfo y la gloria. La política contra el fútbol. La ideología contra la camiseta.

Casullo justifica su apoyo al Mundial Argentina 78 como una decisión meditada, consciente de esta contradicción, que trataba de hacer justicia a la formación política de las clases populares en contra de los gestos y de las ideas peregrinas del "intelectualismo de izquierda" que creía representarlas con mayor fidelidad y conocimiento.

Por supuesto tuvimos plena conciencia de la instrumentación que el Estado de Terror hacía de ese mundial [...] Pero también sentíamos que el fútbol [hacía] a esa identidad intransferible, futbolística, de lo humano argentino (1998, p. 240).

Si para los exiliados el conflicto se presentaba entre apoyar a los jugadores de la selección y denunciar a los organizadores del certamen; para los escritores que vivían en el país, el debate había tomado otra forma, especie de iteración de la máxima populista "Alpargatas sí, libros no": el fútbol contra la cultura, "pan y circo" contra intelecto. En vez de celebrar el triunfo, Borges se había alegrado con un "Por fin concluyó esta fiesta canalla" (citado en Bauso), mientras Ernesto Sabato declaraba:

Prefiero no polemizar con Borges (pero) yo no me considero un imbécil, y me apasiona el fútbol $[\ldots]$ me conmueve la reserva de pasión nacional que hay en nuestro pueblo (Blaustein y Zubieta, 1998, p. 251).

Porque los términos de fondo que se plantean en la controversia tanto fuera como dentro del país tienen su origen 
en el reconocimiento de una ironía de la historia: los aficionados argentinos, en el exilio o no, veían en el triunfo de la selección los merecidos frutos de una rica y esforzada tradición futbolística que llamaban a una celebración abierta, pero ese momento de gloria coincidía con el momento más luctuoso de la historia del país. Era difícil compartimentar las razones del festejo, y fácil entonces malinterpretar las fuentes de la alegría popular.

El exilio parisino es el caso emblemático de esta contradicción, como explica en detalle el texto de Marina Franco: la ciudad fue el foco de una campaña de boicot al mundial argentino, que lo construía como una especie de versión en "farsa" de la "tragedia" que habían sido las olimpiadas de 1936 organizadas por el nazismo. Si bien el gesto original hacia el boicot había surgido en el exilio sueco, en París logró organizarse con eficiencia, cobró mayor notoriedad y visibilidad. Pero, por razones que muy convincentemente enumera Franco, la campaña era más francesa que argentina, y el apoyo de los grupos de exiliados al boicot fue escaso.

En lo que sigue vamos a tratar de acercarnos a la forma que esta tensión adoptó en la representación cultural por parte del exilio, incluso si esa forma fue el vacío. En primer lugar, vamos a describir en líneas generales la posición casi homogénea que el exilio argentino, un colectivo por demás heterogéneo, adoptó respecto del mundial. Luego vamos a preguntarnos cómo interactuaron las fuerzas in situ y el activismo desde el exterior en sus esfuerzos por construir una imagen de la Argentina a través del mundial. Finalmente, vamos a analizar y discutir Cuarteles de invierno de Osvaldo Soriano, un texto que, desde el 
exilio europeo, resume mejor que ningún otro esta disyuntiva al combinar estrategias directas e indirectas en su representación de la copa del mundo. Cuarteles de invierno logra una de las mejores pinturas del clima represivo de la dictadura argentina esquivando referencias directas a la ESMA o a Videla. Pero Soriano, uno de los escritores argentinos más asociados al imaginario del fútbol y parte fundamental de cualquier antología sobre el tema en la tradición literaria nacional, hace, en su mejor novela, un análisis lúcido del mundial sin mencionar una sola vez a César Luis Menotti, Leopoldo Luque, o Mario Kempes.

Ya antes de que fuera cuestionado ideológicamente como un acto de propaganda, el mundial 78 se había convertido en centro de un escándalo de índole económica. La decisión de la dictadura que toma el poder el 24 de marzo de 1976 con el derrocamiento de Isabel Martínez de Perón de llevar a cabo el evento según lo acordado por administraciones previas (la organización de la copa del mundo había sido adjudicada a la Argentina en 1966, Gilbert y Vitagliano, 1998, p. 11) fue parte crucial de la estrategia mediática de construcción y proyección de una imagen positiva del país y del régimen. Pero es bien sabido que Argentina no estaba en condiciones económicas de afrontar la organización de un evento calificado de "faraónico" (Alabarces, 2008, p. 115). El empeño de la dictadura en hacerlo, en apenas dos años, en contra del consejo de sus propios asesores económicos, como Juan Alemann, y aunque el país no contara con la infraestructura edilicia, de transporte o 
tecnológica para llevarlo adelante, ni estuviera en situación organizacional, logística o siquiera anímica de ocuparse de tal empresa habla de su enorme valor simbólico y su gran potencial político. Que la Argentina lograra ejecutar con éxito un evento como la copa mundial de fútbol transmitía a la opinión pública, nacional e internacional, al menos tres mensajes: primero, que la sociedad, el gobierno y las instituciones estaban en condiciones de enfrentar un desafío organizativo mayor, y por tanto, que reinaba en el país una situación de "orden" social; segundo, que el régimen de facto contaba con el apoyo de la comunidad internacional, que con la participación de los múltiples equipos nacionales legitimaba simbólicamente a la Junta; tercero, que con su asistencia masiva a los partidos y eventos del mundial, el pueblo argentino también sancionaba su aprobación al régimen, declaraba su conformidad con la situación, y expresaba incluso su alegría - al cabo el mundial era cansinamente referido en la prensa local como "la fiesta máxima del pueblo" (Menotti, citado en Blaustein y Zubieta, 1998, p. 244). Así, según Franco:

La Junta Militar utilizó [el campeonato] como un movilizador político de primera magnitud, no solo por el potencial del fútbol como factor de identificación colectiva, sino porque su realización en la Argentina era la ocasión de hacer del evento una auténtica causa nacional (2008, p. 181).

En definitiva, el rédito en términos simbólicos era tan positivo para la dictadura que bien valía la inversión de más de quinientos millones de dólares que la economía del país no podía afrontar, y de los que recuperaría apenas diez millones (Alabarces, 2008, p. 117). 
Pero sin duda el centro de la discusión era de orden ideológico y político, y la lucha se daba, como describíamos más arriba, entre el exilio que rechazaba por un lado con su propia existencia el proyecto aberrante de la dictadura y celebraba, por otro, el logro deportivo, y el discurso oficial argentino (materializado no solo por la postura de la dirigencia, sino también por la mayor parte de la prensa, deportiva o no) que defendía a ultranza el mundial como expresión legítima del ser nacional contra lo que había identificado como una "campaña antiargentina" desde el exterior.

El libro de Marina Franco ofrece el mejor análisis de la situación de los exiliados frente a la encrucijada del mundial de fútbol, si bien enfocado solo en el caso del exilio en Francia. Según Franco, una vez que las diversas redes de activistas y militantes franceses implantaron, con rigurosa lógica política, el boicot al mundial, queda "explicar por qué los argentinos se vieron tan divididos por el tema y les resultó tan difícil adherir a la propuesta" (2008, p. 187). La explicación se articula en cinco factores: primero, organizaciones argentinas como el PRT (Partido Revolucionario de los Trabajadores) y Montoneros (el grupo armado más visible y organizado) estuvieron decididamente en contra del boicot, argumentando que era una ocasión para que el mundo viera la verdadera Argentina. Pero también - en un espíritu similar al del análisis de Casullo porque "Promover el boicot era desconocer el sentimiento de las masas" (Álvarez, citado en Franco, 2008, p. 190). Segundo, las diferencias en los modos de hacer política entre franceses y argentinos, que en términos prácticos puede traducirse como la incomprensión francesa de las dinámicas dentro del peronismo, 
generaron actitudes de desconfianza entre un grupo y otro. Tercero, razones de índole emocional, "la tradicional pasión popular de muchos argentinos por el fútbol y su peso en el entramado de símbolos nacionales altamente movilizantes" (2008, p. 192). Cuarto, muchos de los exiliados estaban todavía en proceso de adaptación a su nueva sociedad receptora y no estaban en condiciones ideales para llevar adelante una práctica política efectiva - desde el dominio del francés hasta la familiaridad con códigos políticos y sociales franceses. Finalmente, el hecho mismo de que el boicot respondiera más a dinámicas del campo político local que a la de los exiliados: "la percepción de estar frente a un debate político francés tal vez haya aumentado la distancia o ajenidad de los emigrados argentinos frente al tema" (2008, p. 202). Este mismo análisis puede hacerse extensivo a la escasa representación que el apoyo de los exiliados al mundial encuentra en los textos del exilio: se trata de una situación difícil de explicar en términos políticos, que contradice los lugares comunes de la construcción imaginaria del exiliado - dogmatismo político que se traduce en permanente estado de militancia y activismo, idealización del lugar perdido, un humor nostálgico y apesadumbrado.

En todo caso, el boicot fue un fracaso en términos operativos. Ni logró la ratificación oficial por parte de ninguna nación participante (todas las delegaciones que habían clasificado para jugar el certamen asistieron), ni consiguió que el público desenfocara su atención de las alternativas del certamen durante el mes de junio de 1978. Pero la organización del mundial también fracasó en términos de convocar la adhesión decidida de la comunidad internacional. En términos de 
asistencia, de los cincuenta o sesenta mil turistas que se estimaba llegarían al país, la cifra alcanzó apenas los siete mil (Alabarces, 1998, p. 117).

El exilio logró sin embargo imponer en el consumo mediático del mundial sus propias agendas: llamar la atención sobre la situación de los derechos humanos en la Argentina y exponer la falta de legitimidad del gobierno de facto de la Junta militar. El surgimiento mismo de un plan de boicot que resultara más efectivo como aglutinante en la comunidad política extranjera que en el mismo grupo de exiliados es evidencia de este éxito, como lo son también en ese contexto ciertas iniciativas de gobiernos extranjeros. Según Silvina Jensen el mundial

desempeñó un rol central en la instalación del "tema argentino". Si bien para entonces el régimen militar acumulaba varias sanciones de la comunidad internacional (Amnesty International, Parlamento Europeo, Naciones Unidas), la popularidad del fútbol hizo que se hablara de la Argentina durante casi un mes y que incluso en las páginas de la prensa deportiva se colaran referencias a los "campos de concentración” y a los “desaparecidos" (2010, pp. 49-50).

Asimismo, la celebración del mundial aceleraría el proceso de cuestionamientos por parte de los Estados Unidos, especialmente mediante la injerencia de Patricia Derian, subsecretaria para los Derechos Humanos y Asuntos Humanitarios del Departamento de Estado durante la administración Carter.

La presión norteamericana obligaría $[. .$.$] a que la Junta$ accediera, durante el Mundial, a invitar a la Comisión Interamericana de Derechos Humanos (CIDH) de la OEA 
para que sacara sus conclusiones sobre el problema argentino" (Gilbert y Vitagliano, 1998, p. 48),

visita que se concretaría en septiembre de 1979.

Afirma Franco:

el Mundial se llevó a cabo [...] en un momento de enorme presión internacional por la violación de los derechos humanos y suscitó en el exterior un fuerte movimiento contra el régimen. A su vez, esto fortaleció la denuncia militar de una 'campaña antiargentina' montada desde el exterior. Paradójicamente, el efecto del movimiento externo contra la dictadura fue unificar bajo las banderas deportivas y en defensa de la 'nación agredida' a buena parte de la población argentina (2008, p. 181).

Es indudable que el exilio y la dictadura estaban en una escalada retórica por dominar el discurso público, pero es notable el impacto que la acción del exilio tuvo en el delineamiento de los términos del debate interno en Argentina y de las estrategias de representación del mundial en la prensa y el discurso oficial local. Un mero recorrido por la cobertura de diarios y revistas, la lectura de entrevistas a los protagonistas del momento y a figuras de la cultura, o una revisión de los comunicados oficiales de los miembros del gobierno de facto o del EAM (Ente Autárquico Mundial, la institución creada por el régimen para la organización del evento) bastan para identificar el tema de la "campaña antiargentina" y las críticas a la organización emitidas desde el exterior como eje central de la articulación mediática del mundial para el público local: desmentir, contestar, contrarrestar, reivindicar, rectificar son las acciones que dominan el discurso, claramente en posición 
defensiva. Así, eran los exiliados quienes definían los términos y colonizaban discursivamente el espacio nacional.

El tono hiperbólico que prevalece en la disputa entre exilio y nación contrasta con la opción por la omisión, una de cuyas variantes vamos a tratar de discutir en Cuarteles de invierno de Osvaldo Soriano. Es notable la observación de Alabarces:

Frente al Mundial, en el clima exitosamente represivo que la dictadura instala desde 1976, solo caben dos voces disidentes: la del exilio, que no circula en la Argentina y que no nos sirve como fuente para interpretar la lectura interna del fenómeno - justamente por su condición exterior-; y la del ya entonces nombrado como "movimiento del rock nacional", que en su publicación más exitosa y representativa, la revista Expreso imaginario, opta por la más radical de las disidencias: el silencio absoluto. El Expreso... no hace ninguna mención al torneo en todo el año 1978 (p. 121).

Hemos propuesto, en contraste, que la voz del exilio sí es una fuente válida para interpretar la lectura interna del fenómeno, pero queremos rescatar el silencio como un gesto que también atraviesa el pensamiento del exilio. Por un lado, hemos ya notado la llamativa ausencia del mundial y sus festejos en los textos del exilio. Ahora queremos interpretar una vía alternativa para su representación en la función alegórica que domina el texto de Soriano.

Cuando comienza su exilio europeo en Bruselas en 1976, Osvaldo Soriano era ya un periodista consolidado, pero aún un novelista emergente. Apenas había publicado en 1973 su primera novela, Triste, solitario y final. En Europa (en un periplo que incluye Bélgica, Francia, Italia) escribe el díptico de Colonia 
Vela, sus dos textos más logrados: No habrá más penas ni olvidos y Cuarteles de invierno, que no publicaría en Argentina hasta 1982, cuando la dictadura está ya en retirada y Soriano a punto de regresar al país. Ambas novelas son profundamente referenciales de la situación política argentina, pero proceden por medio de la elipsis, la analogía, la alegoría. Ana María Shua reaccionaba así ante su escritura: "Soriano estaba contando lo que todos llamábamos nuestra historia reciente, esa lucha entre la izquierda y la derecha del peronismo, como si fuera una película de cowboys" (Citado en Soriano, 2003b [1974], pp. 144145). La observación evidencia el carácter analógico de la construcción de las novelas, su voluntad de cifrar la historia en un esquema textual abierto y accesible, aunque desplazado. Una serie de denominaciones relacionadas con esta idea fueron puestas en juego en su momento: Soriano en ocasiones designó su técnica como "metafórica" y en otras la refirió como la escritura de una "parábola", la crítica apuntó el sentido "paródico" de los textos, y sus primeros detractores hablaron de "simplificación". Aunque no desde el rigor terminológico, en todos los casos se destacaba el talante voluntariamente alegórico del proyecto.

Sobre la escritura de Cuarteles de invierno, la novela en la que vamos a concentrarnos aquí, dice Soriano: "[La] escribí entre 1977 y 1979 tratando de exorcizar lo que estaba pasando en la Argentina después del golpe" (Citado en Soriano, 2003a [1982], p. 187). El evento más prominente de ese período es el mundial de fútbol, que se convierte en el referente apenas velado del episodio central de la novela. Conviene entonces referir aquí brevemente la línea central de su argumento: la acción tiene 
lugar en Colonia Vela, en la provincia de Buenos Aires, durante las fiestas de conmemoración del aniversario del pueblo. El espacio está dominado por la presencia de las fuerzas armadas, a cargo también de la organización de los festejos, para los que han contratado a Andrés Galván, famoso cantor de tangos, y a Tony Rocha, boxeador. Recalcando el clima opresivo del pueblo, aparece por la mañana una pintada denunciando a Galván y Rocha de complicidad con las fuerzas armadas. La denuncia da lugar a un episodio clave del texto: cuando están viendo las pintadas, unos paramilitares se les acercan a pedirles autógrafos: Rocha lo da, pero Galván se niega. Después de un breve intercambio y un amago de pelea se revisa la situación de Galván: su contrato es cancelado. Está en camino de vuelta a la capital cuando advierte que la pelea entre Rocha y su contrincante, un oficial del ejército, está arreglada y vuelve a ayudarlo. Rocha efectivamente pierde (la pelea en sí es el momento climático del relato) y queda en tan mal estado que Galván debe llevarlo inconsciente al hospital del pueblo, y luego en tren a Buenos Aires.

Soriano es, como Fontanarrosa y tantos otros, un escritorfutbolista-hincha, que siguió con interés el mundial 78 desde su exilio europeo. Aun así, en la multiplicidad de textos sobre fútbol que aparecen dispersos en sus varios volúmenes de cuentos y que fueron póstumamente reunidos en Arqueros, ilusionistas y goleadores (2006), casi no se menciona la copa mundial. En su reciente 78. Historia oral del mundial, un largo y documentado volumen que revisa todas las fuentes relevantes sobre el asunto - libros, periódicos, revistas especializadas, revistas de interés general, archivos audiovisuales $-\mathrm{y}$ que se 
apoya además en entrevistas hechas especialmente, Matías Bauso recoge apenas tres declaraciones de Osvaldo Soriano. En ellas se condensa muy sintéticamente el ambiente que hemos resumido más arriba: una comunidad escindida entre la conducta política correcta y el irracional amor por la camiseta. En el caso de la experiencia personal de Soriano en París, sus comentarios dejan entrever sobre todo su soledad: a Cortázar el mundial le era indiferente, al resto de sus amigos no le gustaba el fútbol, el único al que sí le gustaba, boicoteaba el evento: "Hubo hasta quien quería que perdiera Argentina. A mí no me daba el cuero para tanto" (Bauso, 2018, loc. 10694). Reflexionando con extrañeza sobre el contraste entre la naturaleza misma del evento (el primer título mundial para el país) y el contexto en que a él mismo le toca vivirlo (solo en un minúsculo departamento parisino) concluye Soriano: "Entonces me di cuenta de que el campeón del mundo era yo solo" (Bauso, 2018, loc. 10702). Esta reflexión tiene una enorme resonancia afectiva con la conclusión de la novela que en ese momento se encontraba escribiendo.

Ante la escasez de reflexiones directas sobre el mundial 78, Cuarteles de invierno, texto de escritura contemporánea a los eventos, adquiere una enorme elocuencia. El punto en que la novela cifra su representación del mundial es la pelea entre Rocha y Marcial Sepúlveda, un oficial del ejército argentino, más joven que Rocha, quien está de hecho en plena decadencia como pugilista. Los rasgos que la pelea en Colonia Vela conserva del mundial son los de su construcción como evento público: la pelea es, en palabras del líder civil local a cargo de la organización, un evento "popular" y está manejado como una 
estrategia para la presentación pública del sistema de valores institucionales que está en el poder. Sepúlveda lo expresa muy claramente en un discurso antes de la pelea:

Mi capitán, señores oficiales de las fuerzas armadas, señoras y señores: la ciudadanía y el ejército al que pertenezco con honra, me han otorgado una misión en un frente que por distintas razones ha estado siempre en manos de civiles. El frente deportivo. Allí estoy combatiendo y conmigo combaten todos mis camaradas. Como ayer en la guerra, donde vencimos con tantos sacrificios, hoy venceremos también en la paz. Pueden confiar en mí como siempre han confiado en los soldados de la patria. Pronto traeré a Colonia Vela la corona argentina y después la del mundo. Yo seré campeón y conmigo el verdadero país será campeón. (2003a [1982], pp. 135-136).

En efecto, Sepúlveda vence a Rocha y avanza, así, hacia la pelea por el título argentino. Colonia Vela es un pueblo construido vía sinécdoque como una imagen del país, y en tanto espectáculo público, la pelea es una imagen del mundial. El organizador, así como múltiples carteles en el pueblo anunciando los eventos de los festejos, destaca: "el esfuerzo y la voluntad de las fuerzas armadas al organizar esta fiesta para la ciudadanía" (2003a [1982], p. 31).

El procedimiento más complejo de la articulación alegórica del mundial en el enfrentamiento entre Rocha y Sepúlveda es la disociación de la selección argentina en dos elementos que se oponen. Como lo identifica el discurso de Sepúlveda, "soldados" y "civiles" son dos bandos en pugna, pero ambos representan, de algún modo, a la selección nacional en el mundial 78. Hacia el final de la novela, cuando Galván lleva a 
un Rocha inconsciente de vuelta a Buenos Aires y revisa su billetera para averiguar su dirección, hay una detallada y sutil construcción de Rocha como imagen analógica del pueblo argentino: la cédula de identidad de Rocha revela que su fecha de nacimiento coincide con el aniversario de Colonia Vela, que él y el pueblo cumplen años el mismo día. Su edad, por otra parte, treinta y cinco años, lo pone a fines de los setenta como un sujeto formado en la Argentina de Perón, que se inicia aproximadamente treinta y cinco años antes, el 17 de octubre de 1945. Así, Rocha representa un aspecto del seleccionado nacional. Pero Sepúlveda guarda también una relación de sinécdoque al ser parte del organismo que se define a sí mismo como "el verdadero país". Si en la concepción esquemática que el texto atribuye al oficial Sepúlveda el enfrentamiento de esa noche es entre el "verdadero país" y el otro país, la lógica del relato incorpora toda una serie de móviles y asociaciones de los respectivos bandos. Así, construye un combate entre civiles y militares, entre oprimidos y opresores, entre resistencia y represión, pero también entre un país que mantiene la especificidad de las funciones de los militares y un país intervenido. La representatividad de Rocha se vuelve así un componente clave de la construcción alegórica del texto. Como lo expresa Galván: "Parece que va a pelear contra todo el ejército, compañero" (2003a [1982], p. 135).

Como solo uno de los dos contrincantes puede triunfar, la construcción en la novela de "triunfo" y "derrota" complica todavía más la lectura del mundial de fútbol desde el exilio, y le impone un sentido ético al que vamos a volver hacia el final. La escenificación de la derrota personal de Rocha funciona en 
términos colectivos. El combate representa en distintos niveles la pugna nacional y, así, cada figura individual (Rocha y Sepúlveda) es alegoría de la Argentina. Pero, como decíamos antes, es finalmente el cuerpo de Rocha el elemento textual que más claramente asume la significación del cuerpo nacional. Detrás de la euforia por el resonante triunfo del local, la escena de la pelea termina dando una nueva dimensión a la inercia colectiva, que se despega de su puro papel defensivo para adquirir ya el cariz de complicidad con que se puede explicar el comportamiento de la sociedad civil durante la dictadura (Vezzetti, 2002, p. 135) -y que las primeras acciones de la redemocratización revertirían, devolviendo "a la sociedad una imagen de tranquilizadora inocencia" (2003a [1982], p. 110):

Me paré y empecé a empujar a los tipos que todavía estaban sobre el ring. [...] Tiré a un par de muchachones contra las cuerdas y empecé a gritar. Hasta que me di cuenta de que nadie hablaba, que la gente estaba quieta, mirándonos sin mover un músculo, como en un repentino velorio. Y seguía lloviendo (2003a [1982], p. 163-164).

El gesto más arriesgado y comprometido de Soriano en la construcción de una imagen ligeramente cifrada del mundial de fútbol es hacer de Rocha el perdedor. Parece operar aquí una lógica de género: la de la literatura y el cine de box, que recaen habitualmente en el rescate romántico de la figura del perdedor. Pero la afirmación de Soriano se hace extensiva al país, y redefine el triunfo histórico de la selección argentina en el mundial 78. Es claro que su análisis tiene más que ver con un modelo ético que con uno deportivo o histórico. Reelaborar la copa del mundo en términos de derrota es una forma de 
expresar un juicio sobre el evento, el desempeño del equipo argentino y el valor simbólico del resultado.

Pero no es eso todo lo que hace la novela al reconfigurar la competencia entre naciones como una competencia entre facciones de una nación. A la vez que el elemento popular es presentado como un esfuerzo heroico, digno, genuino, y redimido a través de la derrota, el elemento prepotente, corrupto, ilegítimo, es "condenado" a través de un triunfo no honorable. De un modo u otro el análisis narrativo de Soriano está incorporando las suspicacias en torno al dudoso pero necesario triunfo de la selección argentina por 6 a 0 ante Perú, que le permitió avanzar a la final con Holanda. Pero también está dando cabida a la fe en la noción de que los partidos ganados fueron ganados. Esta escisión en dos es un modo simple, didáctico, pero efectivo de darle forma a los conflictos éticos que dominaban a los protagonistas en el campo de juego, a los espectadores en la tribuna, y a esos críticos de la dictadura que sin embargo no adherían al boicot del mundial, desde el exilio.

En la inopinada (y quizás involuntaria) defensa que Damián Tabarovsky hace de Soriano cuando lo desacredita en su influyente libro Literatura de izquierda, se deja ver el éxito de esta operación de Soriano - y de los escritores del exilio en general:

Desde finales de los 80 se desarrolló una inmensa narrativa reaccionaria, una vuelta sobre las versiones más conservadoras de la literatura. ¿Puede pensarse la fascinación que produjo el realismo sucio entre los incipientes escritores como producto de otra década que no sea la del 90? ¿Cómo puede entenderse el éxito ya no solo de mercado, sino ético, de Soriano y el sorianismo? (2004, p. 59). 
Soriano había reconocido en una entrevista de 1992 la hostilidad del ambiente literario argentino, en que "la pedantería es solo comparable a la del mundo del box" (Speranza, 1995, p. 63), hacia su condición de contador de historias, à la Dumas, pero había exigido también el reconocimiento y el respeto en la diferencia. Más allá de los cuestionamientos al papel de Soriano en el campo cultural nacional, es interesante la delimitación del plano en que triunfa su literatura, según Tabarovsky: el plano ético. En una ordenación a grandes rasgos de la narrativa argentina desde la década de los setenta, Soriano representa -no por sí mismo, sino junto a escritores tan diversos como Antonio Di Benedetto, Mempo Giardinelli o Tomás Eloy Martínez y otros de destino más trágico como Rodolfo Walsh, Haroldo Conti o Paco Urondo, es decir, los exiliados y los asesinados - el fracaso del proyecto político de la izquierda revolucionaria en la Argentina. Es la fracción de escritores exiliados la que materializa más eficientemente este fracaso en el imaginario nacional. El regreso de los escritores exiliados - paulatino, poco promocionado, y en algunos casos solo tentativo- pone en evidencia el nuevo mapa de fuerzas que rige el campo intelectual de un país efectiva y forzosamente "reorganizado" y el motus central de la etapa en ciernes: cerrar y digerir tan pronto como fuera posible la etapa anterior, programa en que las novelas de Soriano cumplieron un rol decisivo.

Cuarteles de invierno es, así, el mejor ejemplo de la crisis de conciencia que el mundial 78 generó en los exiliados argentinos. Incapaces, por la causa que fuera, de incluir el evento deportivo y el triunfo - aún si teñido de sospechas - de la selección nacional en el mismo firme ataque que le hacían al régimen 
dictatorial y el estado de terror que había impuesto en el país, se encontraron en la incómoda situación de justificar su ambigüedad o desdibujar su inconsistencia. Algunos, como Casullo en el ejemplo con que empezamos esta discusión, lo hicieron con una lógica impecable, aunque igualmente poco convincente. Si bien los exiliados lograron imponerse en el debate sobre el tema al punto de darle forma a la estrategia interna con que presentar y promocionar el mundial, no consiguieron articular con claridad una estrategia para conciliar su posición ideológica con su corazón de aficionados al deporte nacional. El impulso libidinal sojuzgó a la lógica política. En general, Freud triunfó sobre Marx entre los exiliados. Soriano, sin embargo, tal vez por su mayor familiaridad desde adentro con el mundo del fútbol, tal vez, irónicamente, por su mero dogmatismo, resolvió de otro modo el dilema y logró darle narrativamente una forma a la vez problemática y redentiva.

\section{Referencias bibliográficas}

Alabarces, P. (2008). Fútbol y patria. El fútbol y las narrativas de la nación en la Argentina. Buenos Aires: Prometeo.

Bauso, M. (2017). "Un ciego mirando al sol. Borges y el Mundial 78”. https://medium.com/@matiasbauso/un-ciegomirando-al-sol-borges-y-el-mundial-78-6d8627do464b

---. (2018). 78. Historia oral del mundial. Buenos Aires: Sudamericana. Kindle Edition.

Blaustein, E., y Zubieta, M. (Eds.). (1998). Decíamos ayer. La prensa argentina bajo el proceso. Buenos Aires: Colihue. 
Casullo, N. (1998). "Mi mundial 78 en México, con Ildefonsa". En Blaustein, E., \& Zubieta, M. (Eds.). Decíamos ayer. La prensa argentina bajo el proceso. Buenos Aires: Colihue, 234-242.

Franco, M. (2008). "Derechos humanos, política, fútbol y ciencia”. El exilio. Argentinos en Francia durante la dictadura. Buenos Aires: Siglo XXI, 181-206.

Gilbert, A., y Vitagliano, M. (1998). El terror y la gloria. La vida, el fútbol y la política en la Argentina del Mundial 78. Buenos Aires: Norma.

Jensen, S. (2010). Los exiliados. La lucha por los derechos humanos durante la dictadura. Buenos Aires: Sudamericana.

Soriano, O. (2006). Arqueros, ilusionistas y goleadores. Buenos Aires: Seix Barral.

---. (2003a [1982]). Cuarteles de invierno. Buenos Aires: Seix Barral.

---. (2003b [1974, 1980]). No habrá más penas ni olvido. Buenos Aires: Seix Barral.

Speranza, G. (1995). Primera persona. Conversaciones con quince narradores argentinos. Buenos Aires: Norma.

Tabarovsky, D. (2004). Literatura de izquierda. Rosario: Beatriz Viterbo.

Vezzetti, H. (2002). Pasado y presente. Guerra, dictadura y sociedad en la Argentina. Buenos Aires: Siglo XXI. 